\title{
Emergency department targets: a watershed for outcomes research?
}

\author{
Early evidence is encouraging, but guarded optimism is advised
}

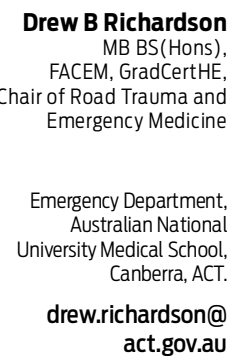

doi: $10.5694 / \mathrm{mjal} 2.10003$ ational Emergency Access Targets (NEAT) are now in place and will progressively require a higher proportion of emergency department (ED) patients to be treated and to leave within a set time frame over the next 4 years. The stated aim of the NEAT is to improve patient safety and patient access; their implied aim is to reduce overcrowding. The funding model recognises that the causes of overcrowding often lie outside of the ED, providing states with upfront resources with which to reengineer hospital processes. ${ }^{1}$ From a researcher's perspective, this "natural experiment" will provide an opportunity to address two major questions: what are the best hospital models of care for rapid and safe ED flow and what is the effect on patient outcomes?

Overcrowding in the ED is strongly associated with excess patient mortality, both inside and outside of hospital. ${ }^{2-4}$ It is largely accepted that overcrowding contributes to dysfunction that might increase mortality, but demon- strating causality requires strength of association, consistency, specificity, temporality, a dose-response relationship, biological plausibility, coherence, reversibility and consideration of alternative explanations (the Bradford-Hill criteria $\left.^{5}\right)$.

Given the considerable difficulties that would be encountered in attempting a randomised trial, observers have been waiting for mortality reports from a setting where effort has been made to reduce overcrowding. The first such evidence of apparent reversibility is published in this issue of the Journal. Geelhoed and de Klerk ${ }^{6}$ describe the first year of Western Australia's 4-hour rule in Perth hospitals, finding a $13 \%$ overall reduction in mortality in the three large hospitals where ED overcrowding also diminished.

This certainly adds something to the evidence for a causal relationship between overcrowding and unnecessary patient deaths. The 80 fewer deaths recorded in the 
tertiary hospitals in one year represents a magnitude of almost half the state road toll, and if this can be achieved largely by reorganising and streamlining hospital processes, then NEAT will have significant public health implications. However, methodological issues with the research suggest that further research is required.

Without either age-specific data or matched controls, external factors causing the reported changes in mortality over time cannot be excluded. Death has obvious advantages as an outcome measure - it is final, routinely and accurately recorded and generally undesirable - but raw mortality statistics need to be treated with caution in a time-series study. The analysis showing monthly access block is a better predictor of mortality than the linear underlying trend suggests a real effect, but patient age remains a possible confounder. For example, between 2008 and 2009, the absolute number of deaths in Perth fell from 9254 to 8987 while the population rose by over 52000 , and yet the Australian Bureau of Statistics reports that agestandardised mortality barely changed, from 5.7 to 5.6 per 1000 people. ${ }^{7}$ The cohort reaching the end of their life expectancy was briefly dominated by the small subset who were born in the early years of the Great Depression. With similar reasoning, a major increase in raw mortality but little age-specific change is expected from the babyboomer generation in a few years' time.

Geelhoed and de Klerk's study defined mortality in terms of death during the hospital episode beginning in the ED, rather than death recorded in the hospital or in the state within a defined period, as used by other researchers. ${ }^{2-4}$ Hospital episodes are poorly defined administrative events, rather than research descriptions, and should only be considered valid in a time series if there are no changes in recording practice. Although the study does not provide a breakdown of episode length or alternative episode outcomes, there are strong indications that episodes were not recorded consistently between institutions or over time.

The reported mortality in small hospitals was surprisingly low, most likely because many high-risk episodes were terminated by transfer to a larger hospital, with the attendant chance of double counting if the patient were admitted through the larger ED. The number of admissions increased by $46 \%$ over 4 years, despite little change in inpatient bed numbers in WA (reportedly, about 2.5 available public hospital beds per 1000 population in the financial year $2007-08^{8}$ and about 2.4 in $2008-09^{9}$ ). Thus, the average length of admission episodes must have decreased by at least $40 \%$. This raises the possibility that some of this was achieved by alterations in recording practice, such as increased use of "statistical discharges", which occur when a patient who was admitted through the ED begins a new episode of care without changing beds. If such a patient dies, his or her death may not be recorded as being linked to an episode that began in the ED.

These issues do not invalidate the premise that overcrowding in the ED causes mortality but are sufficient to say that the research by Geelhoed and de Klerk should not represent the last word on the matter. As NEAT are rolled out in 2012, researchers look forward to large, well controlled examinations of all the patient outcomes. The study from Perth should be regarded as an encouraging first report.

\section{Competing interests: No relevant disclosures. \\ Provenance: Commissioned; externally peer reviewed.}

1 Council of Australian Governments. National Health Reform Agreement National Partnership Agreement on Improving Hospital Services. Canberra: COAG, 2012. http://www.yourhealth.gov.au/internet/yourhealth/ publishing.nsf/Content/npa-improvingpublichospitalsagreement\#.TxO2KdXIrAU (accessed Jan 2012).

2 Guttmann A, Schull MJ, Vermeulen MJ, Stukel TA. Association between waiting times and short term mortality and hospital admission after departure from emergency department: population based cohort study from Ontario, Canada. BMJ 2011; 342: d2983.

3 Richardson DB. Increase in patient mortality at 10 days associated with emergency department overcrowding. Med J Aust 2006; 184: 213-216.

4 Sprivulis PC, Da Silva J-A, Jacobs IG, et al. The association between hospital overcrowding and mortality among patients admitted via Western Australian emergency departments. Med J Aust 2006; 184: 208-212.

5 Hill AB. The environment and disease: association or causation? Proc $R$ Soc Med 1965; 58: 295-300.

6 Geelhoed GC, de Klerk NH. Emergency department overcrowding, mortality and the 4-hour rule in Western Australia. Med J Aust 2012; 196: 122-126.

7 Australian Bureau of Statistics. Deaths, Australia, 2010. Canberra: ABS, 2011. (ABS Cat. No. 3302.0.) http://www.ausstats.abs.gov.au/Ausstats/ subscriber.nst/0/9B3E4D59EBC57ABBCA257943000CF5E2/\$File/ 33020do004_2010.xls

8 Australian Government Department of Health and Ageing. The state of our public hospitals, June 2009 report. http://www.health.gov.au/internet/main/ publishing.nsf/Content/health-ahca-sooph-index09.htm (accessed Jan 2012).

9 Australian Government Department of Health and Ageing. The state of our public hospitals, June 2010 report. http://www.health.gov.au/internet/main/ publishing.nsf/Content/sooph10 (accessed Jan 2012). 